\title{
LA CRISIS DE LA SOCIALDEMOCRACIA: LAS IZQUIERDAS CHILENAS REFRACTADAS*
}

\author{
Alfredo Joignant \\ Universidad Diego Portales
}

\begin{abstract}
Resumen: El autor define la crisis de la centroizquierda en Chile como parte de la debacle de la socialdemocracia mundial y, a partir de esta experiencia, vislumbra algunas vías estratégicas para superar el momento. Luego, en el plano de los contenidos, argumenta que las izquierdas deben concentrarse en "sacar del mercado" tres derechos sociales: educación, salud y previsión, sin dejar de recordar que, para financiarlos, el crecimiento económico es indispensable. Diseñar un programa de salida gradual del neoliberalismo sería parte de ese desafío.

Palabras Clave: socialdemocracia, izquierdas, crisis ideológica, derechos sociales.
\end{abstract}

\footnotetext{
Alfredo Joignant. Doctor en ciencia política por la Universidad de París I Panthéon-Sorbonne. Profesor titular de la Universidad Diego Portales. Investigador principal de COES. Email: alfredo.joignant@mail.udp.cl.

* Versión revisada de la conferencia presentada en el Centro de Estudios Públicos el miércoles 27 de junio de 2018, con ocasión de la primera parte del seminario "La centroizquierda en Chile. ¿Cómo se llegó a esto? ¿Cómo se sale?”.
} 


\title{
THE CRISIS OF SOCIAL DEMOCRACY: THE CHILEAN LEFT REFRACTED
}

\begin{abstract}
The author identifies the crisis of the centre-left in Chile as part of the breakdown of social democracy worldwide and finds clues in this international experience to possible strategic paths out of the situation. Turning to substance, he argues that the different strands of the left need to concentrate on taking three social rights "out of the market", namely education, health and social security, without forgetting that economic growth is essential to finance these. Designing a programme for a gradual exit from neoliberalism is part of this challenge.
\end{abstract}

Keywords: social democracy, the left, crisis of ideology, social rights.

$D$ uenos días a todos y muchas gracias al Centro de Estudios Públicos por haber organizado este foro. Éste no es el primer foro sobre el tema que nos reúne hoy en el cual he participado, ya que es un tema muy de contingencia y de persistente actualidad: la vigencia del problema que hoy convoca nos acompañará por un buen tiempo, y temo que mi diagnóstico va a ser completamente diferente al de Jorge Correa y Carlos Vergara. Porque el famoso lío de las izquierdas, y de su "centro", no es entendible si sólo se consideran las coordenadas chilenas: a decir verdad, es un fenómeno general. Esto no está pasando sólo en Chile. Es importante entenderlo.

Pero partamos por una nota precautoria, una observación descriptiva sobre el contexto chileno después de las elecciones de 2017: tras las elecciones generales del año pasado, irrumpieron con representación parlamentaria dos izquierdas — quizás más, porque no sabemos cómo va a evolucionar el Frente Amplio_- y se consolidó el desplome (de veras dramático) del centro democratacristiano, orientándose este último hacia alguna forma de fractura. No tengo dudas de que la fractura de la Democracia Cristiana, de no ser orgánica (lo que se conoce como una escisión), se traducirá en una salida a la italiana, con dos almas — más o menos objetivadas - en facciones organizadas o, derechamente, en partidos.

Con ocasión de las últimas elecciones se materializaron, además, las consecuencias de una larga y duradera corrida hacia el centro político por parte del Partido Socialista (PS) y el Partido por la Democracia 
(PPD), lo que había convertido - y travestido - a ambas fuerzas en partidos objetivamente centristas, con sólo retóricas de izquierda en el perímetro de determinadas conmemoraciones y de tales o cuales reformas (como del mercado del trabajo, tributaria, etcétera), restándoles radicalidad. La pérdida de radicalidad es entendible cuando se es partido de gobierno, pero resulta francamente incomprensible, a la vez, que se gobierne con una total inconsciencia de lo que rige la práctica política del propio sector; esto es, entregarse a una colonización de las culturas partidarias bajo un "modelo" que se sustrajo a la crítica proveniente de la racionalidad de los derechos sociales universales, es decir, a la crítica socialdemócrata. Este aspecto de la crisis socialdemócrata nunca ha sido seriamente abordado, y llegó el momento de hacerlo con la misma envergadura de la autocrítica que originó la renovación socialista en los inicios de los años ochenta. Digámoslo de una vez: lo que está ocurriendo en el Chile de izquierdas de hoy es el efecto retrasado de lo que significó la Tercera Vía europea: esa coordinación, más de centro que de centroizquierda, que fue liderada por Tony Blair y el laborismo británico al cabo de un gigantesco coup de force interno al partido, y que supo disfrazar su adhesión al mercado de los derechos con una retórica progresista de demandas de derechos sociales, logrando diferenciarse electoralmente del conservadurismo (aunque no lo suficiente como para hacer imposible el juicio de Thatcher según el cual su mejor herencia fue... Tony Blair). A esto se sumaron, a su manera (pragmática y poco estridente), Gerhard Schröder y el SPD alemán, así como la izquierda italiana detrás del liderazgo de Massimo d'Alema. A veces se olvida, pero esta Tercera Vía europea tuvo un correlato en América del Sur, con la configuración del trío ABC: Fernando de la Rúa en Argentina, Fernando Henrique Cardoso en Brasil y Ricardo Lagos en Chile. Los efectos electorales de esta forma de ser y hacer izquierda se están pagando hoy.

Y lo que se encuentra en juego hoy - cuyo resultado no lo conozco, evidentemente - es una nueva hegemonía dentro de la izquierda, lo que obliga seriamente a dejar de hablar de la izquierda en singular y a razonar en términos mucho más plurales: las izquierdas. Para lograr pensar de este modo era necesario perder las elecciones, ya que la hegemonía no se disputa ni se construye del mismo modo gobernando que siendo oposición. No perdamos nunca de vista que ser gobierno 
acarrea obligaciones y, sobre todo, restricciones; ser oposición supone contraer un contrato con la libertad: es desde ese espacio, entre gobierno y oposición, un intersticio de creación política, que se construye la posibilidad de gobernar de cierto modo y con cierta postura, en donde conservar radicalidad es, además de un desafío, un verdadero problema.

Éste es un momento tremendamente inquietante para las izquierdas, para todas las izquierdas: socialdemócratas, populares y populistas (desde partidos socialistas a epígonos de Podemos).

De nada sirve decir, sobre todo para las izquierdas, algo parecido a: "No, es que esta debacle se da en países desarrollados y no en países de ingreso medio como Chile o como Uruguay"; o de modo más open mind, pero igualmente negador: "Éste no es un tema para países como el nuestro". Lo que nos convoca no es un tema chileno, si aceptamos que lo que estamos presenciando es una crisis general de la socialdemocracia, y, tras ella, una crisis general del socialismo. El negacionismo de este estado de cosas no sólo es torpe; es criminal. Evidentemente, algo de esta debacle se está viendo en el continente con el giro a la derecha en América del Sur. ¿Es sólo política esta crisis? Fundamentalmente sí, pero hay en ella una real crisis intelectual, que se aprecia muy bien en el libro The idea of socialism, ${ }^{1}$ de Axel Honneth, políticamente desafiante e intelectualmente pesimista, así como en el brillante texto Undoing the Demos ${ }^{2}$, de Wendy Brown, cuya reflexión se origina en la fascinación inicial que experimentó Foucault con las formas tempranas del neoliberalismo. ${ }^{3}$ Es a esta altura y en este nivel de complejidad que las izquierdas deben colocarse, rechazando la ilusión del escaño: no es porque se es diputado o senador, con todas las gratificaciones simbólicas y cegueras que la ocupación de un escaño conlleva (olvidando que la mitad del electorado no está votando), que la modificación de la realidad vía reformas tendrá lugar. Son innumerables los ejemplos en los que las izquierdas opositoras han errado, promoviendo reformas estúpidas (prohibir el etiquetamiento de lugares públicos con el nombre de Jaime Guzmán), sin percatarse de las consecuencias segregadoras de

${ }^{1}$ Axel Honneth, The Idea of Socialism: Towards a Renewal (Cambridge, UK: Polity Press, 2017).

${ }^{2}$ Wendy Brown, Undoing the Demos. Neoliberalism's Stealth Revolution (Nueva York: Zone Books, 2015).

${ }^{3}$ Michel Foucault, Nacimiento de la biopolítica: curso en el Collège de France (1978-1979) (Buenos Aires: Fondo de Cultura Económica, 2007). 
otras más (como promover "en buena onda" vagones sexualmente segregados del metro para dificultar el contacto malicioso de hombres en contra de mujeres). ¿Cuál es el desafío? Entender la debacle. ¿Cuál es el problema? Diseñar estrategias para enfrentar la debacle.

Para comprender esta debacle (a decir verdad, de tono electoralmente menor en Chile, aunque de tono mayor si se considera el contenido de la controversia), es imprescindible colocar a esta larga y angosta franja de tierra con su población en el contexto histórico mundial, especialmente en el perímetro de la crisis financiera de 2008-2009: es a partir de estos años que comienza a jugarse el destino de la izquierda global, incluyendo a las izquierdas chilenas.

Es probable que no lo recuerden, pero mucha intelectualidad de izquierda en todas partes —en 2008 y 2009— sostenía que la crisis subprime era tan profunda que nos encontrábamos en el umbral del fin, o del colapso final (lo que es más o menos lo mismo) del capitalismo, y que la salida sería inevitablemente "por la izquierda". Esto no fue lo que ocurrió. Son innumerables los botones de muestra de la debacle: desde la literal desaparición del Pasok ${ }^{4}$ en Grecia hasta la aniquilación a la que fue sometido el socialismo francés en 2017, pasando por el gran debilitamiento del $\mathrm{PSOE}^{5}$ y el $\mathrm{SPD}^{6}$. Salvo contadas excepciones (una de ellas es el laborismo británico liderado por Corbyn), son virtualmente todos los partidos socialistas y laboristas los que se encuentran amenazados.

En el presente, ¿cuáles son las estrategias electorales disponibles? Teniendo a la vista lo que ha ocurrido en Europa, el debilitamiento socialdemócrata en Chile llega varios años después que en el viejo continente: esto es relevante, ya que les permite a las izquierdas criollas leer a tiempo las estrategias que hasta ahora se han ensayado.

Primera estrategia disponible: la competencia sin cooperación entre la izquierda clásica y la nueva izquierda (por ejemplo, España, en la tensa relación entre socialistas y Podemos). Habrá que ver cómo evoluciona este entendimiento limitado con Pedro Sánchez en tanto jefe de gobierno.

${ }^{4}$ Movimiento Socialista Panhelénico, partido político socialdemócrata de Grecia, que gobernó la mayor parte de los años ochenta y noventa.

${ }^{5}$ Partido Socialista Obrero Español.

${ }^{6}$ Partido Socialdemócrata de Alemania. 
Segunda estrategia disponible: la izquierdización sin fractura, lo que se ajusta al caso de Jeremy Corbyn y el laborismo británico. Esta estrategia es tan peculiar como inexportable, ya que se da en el contexto del Brexit y de una severa división interna del Partido Conservador. El éxito relativo del laborismo de Corbyn (40 por ciento de los votos en la última elección parlamentaria, dos puntos por debajo de los conservadores) es una victoria muy personal ante un error de Theresa May, quien buscó aplastar disolviendo a la Cámara Baja. Resultado: el Partido Conservador perdió la mayoría en escaños que tenía, lo que lo obligó a aliarse con los católicos irlandeses. ¿Qué es, concretamente, lo que logró Corbyn? Corbyn logró atraer electorado joven y educado anti Brexit, cuya máxima expresión es el grupo Momentum, junto al viejo electorado pro Brexit, jugando con la ambigüedad. Es precisamente esta combinación, altamente personalizada en su líder, la que hace de esta estrategia un curso de acción realmente inexportable.

Tercera estrategia disponible: la izquierdización con fractura de la socialdemocracia, lo que se materializó en Francia con la competencia fratricida entre los candidatos presidenciales Benoît Hamon (socialista) y Jean-Luc Mélenchon (candidato de La France Insoumise ${ }^{7}$ ). Resultado: Mélenchon arrasó al candidato socialista, lo que se tradujo en una debacle parlamentaria del PS y un vago éxito electoral de sus competidores de izquierda. ${ }^{8}$

Cuarta estrategia electoral disponible: la competencia cooperativa, lo que se expresa en algo parecido a un milagro, en este caso, portugués.

Me quiero detener en el "milagro heterodoxo portugués", vigente desde el año 2015: lo que aquí se produjo es una síntesis de izquierdas. Es a partir de un común rechazo a la austeridad que se pudo formar un bloque de fuerzas entre el Bloque de Izquierda — equivalente al Frente Amplio chileno- con 19 diputados, el Partido Comunista con 15 diputados y el Partido Ecologista Verde con 2 escaños, a quienes se suman 86 diputados socialistas. La llave del éxito es un gobierno exclusiva-

${ }^{7}$ Partido de izquierda fundado por el mismo Mélenchon en febrero de 2016, inspirado en el Podemos español.

${ }^{8}$ Un dato anecdótico, pero simbólico: el Partido Socialista Francés acaba de vender su tradicional sede de calle Solferino, con miras a enfrentar una difícil situación económica. 
mente socialista, liderado por Antonio Costa, sin participación de los socios, con los cuales se negocia separada y puntualmente a partir de un acuerdo básico de rechazo a la austeridad. He aquí algunos elementos del milagro, en donde destaca el aumento del PIB y la caída de la tasa de desempleo, lo que se paga a un cierto precio: grave problema de deuda pública con el sistema bancario. La metodología política sobre la que descansa este milagro es clarísima: el gobierno de Costa negocia a dos bandas permanentemente: con los partidos de izquierda y, paralelamente, con las instituciones comunitarias de Bruselas y el FMI. Ésta ha sido una fórmula electoral y políticamente exitosa, por definición frágil, pero con reactivación de la economía, aumento del sueldo de los funcionarios públicos, aumento de las pensiones, elevación del salario mínimo y disminución del IVA. Me parece evidente que esta fórmula hay que entenderla, y bien pudiese servir de plataforma para las izquierdas chilenas y su apertura al centro democratacristiano.

Pero junto a la irrupción de nuevas izquierdas, hay algo más profundo en esta debacle socialdemócrata, y es posible resumirlo en una sola pregunta: ¿cómo se puede ser de izquierda cuando el eje derecha-izquierda pierde fuerza? Si bien existe evidencia contradictoria en las encuestas chilenas, ${ }^{9}$ me parece que la pregunta es pertinente. ¿Qué hacer cuando hay cada vez menos gente que se autoposiciona en el eje derecha-izquierda? Qué duda cabe: el problema no se plantea en los mismos términos para la gente de derecha, porque las fuerzas que encarnan esa zona del eje descansan en la inercia del orden, mientras que la izquierda necesita impugnarlo.

¿Cuál es el trasfondo de esta debacle? ¿Cuáles son las coordenadas de la amenaza? En el caso europeo, lo que se encuentra en el corazón del problema es la austeridad y la privatización parcial o general de los derechos sociales, así como el envejecimiento de la población, la transformación de la estructura de clases y la elevación general de los niveles de educación (a mayor educación menor lealtad con partidos y mayor autonomía de las personas). Como si esto fuese poco, es preciso tomar nota de la elevación de la esperanza de vida y la creciente auto-

${ }^{9}$ Sobre estas encuestas, es preciso hacer notar que mucho, en sus resultados, depende del modo en que se formula la pregunta referida al posicionamiento en el eje derecha-izquierda, desde el número de posiciones en el eje, hasta la posibilidad explícita de no identificarse con la escala. 
matización del trabajo, cuyos efectos de largo plazo no los conocemos. Consideremos la automatización del trabajo y asumamos que constituye un enigma económico en Chile, pero también político: el Partido Socialista de Chile es una colectividad que se define como una fuerza de trabajadores manuales e intelectuales. Entonces, me pregunto: ¿cómo se puede ser de izquierda apelando a obreros y trabajadores manuales cuando ese tipo de trabajo está destinado a desaparecer?

Mirando hacia adelante, me parece evidente que la tarea de recomposición de las izquierdas en Chile pasa por asumir un horizonte minimalista de reformas, concentrándose en tres $-\mathrm{y}$ sólo tres - derechos sociales orientados a ser satisfechos de modo universal, clásicamente asociados a la socialdemocracia: educación, salud y previsión. Nada menos, pero nada más. La pregunta es cómo financiarlos, bajo qué entramado institucional, ${ }^{10}$ lo que a su vez supone una capacidad pedagógica para persuadir sobre las bondades de una sociedad que descanse en cimientos solidarios. De lo que se trata es de "descomodificar" los derechos sociales, extrayéndolos de la esfera del mercado: lo que a menudo se olvida es que la descomodificación, es decir, su transformación desde la condición de mercancía a lo que en realidad es un derecho, es un asunto de grado (Esping-Andersen lo vio con meridiana claridad).

De existir un horizonte que haga las veces de imán para todas las izquierdas, en su núcleo se encontrarán los derechos sociales. De lo que se trata es de armar un programa de salida del neoliberalismo, ya que Chile fue tempranamente laboratorio de implementación de un modelo de privatización de derechos que permeó la cultura y las conductas. No confundamos este programa de salida del neoliberalismo con un programa de ruptura con el capitalismo, ni menos con una estrategia de entrada al socialismo, que objetivamente no sé en qué podría consistir. Sabemos hacia dónde avanzar: estos tres derechos sociales son el norte mínimo de preservación de una identidad de izquierdas, a la que se sumarán los desafíos civilizatorios de protección del medio ambiente y de una robotización del trabajo y de buena parte de la vida diaria que

${ }^{10}$ En El otro modelo sugerimos un régimen de lo público que supone incorporar en la satisfacción y goce de derechos sociales a agentes privados, a condición de que los chilenos sean tratados como ciudadanos y no como consumidores o clientes. Véase Fernando Atria, Guillermo Larraín, José Miguel Benavente, Javier Couso y Alfredo Joignant, El otro modelo. Del orden neoliberal al régimen de lo público (Santiago: Debate, 2013). 
podrían significar transformaciones políticas insospechadas. Tal es la magnitud del problema.

Este es el horizonte temático del problema de las izquierdas. Suponiendo que exista un acuerdo sobre el diseño institucional de satisfacción de estos tres derechos universales, ¿cómo financiarlos? Evidentemente que sin crecimiento no es posible hacerlo. Las izquierdas deben asumir el problema del crecimiento económico como condición de posibilidad para la satisfacción de derechos: es con crecimiento que se vuelve posible la distribución, sin perder de vista que en esta ecuación hay una gran trampa. Para crecer se necesita confianza, lo que incluye al empresariado y los inversionistas: el problema es que la generación de esa confianza produce pérdida de radicalidad de la socialdemocracia, además de erosionar la autenticidad de la identidad. No sabemos cómo lidiar con esta trampa. El futuro nos dirá si las izquierdas estuvieron a la altura del problema. En esto, nada se encuentra garantizado: ni el éxito, ni menos la supervivencia. EP 